\title{
Subjetividades infantiles femeninas y pedagogías de la cotidianidad*
}

\author{
Children's Feminine Subjectivities and Everyday Life Pedagogies \\ Ingrid Delgadillo Cely ${ }^{1}$
}

Para citar este artículo: Delgadillo, I. (2017). Subjetividades infantiles femeninas y pedagogías de la cotidianidad. Infancias Imágenes, 16(2), 313-325.

\section{Resumen}

Este trabajo pretende contribuir a identificar las subjetividades femeninas infantiles que se han construido mediante la producción y circulación de textos como la Revista Tú — dirigida a un público entre los 9 y los 18 años-. Se busca así evidenciar cómo este tipo de productos culturales están anclados en una pedagogía que rebasa los límites de la escuela y se instala en la vida cotidiana, en la familiaridad de la vida de las niñas y adolescentes, aportando referentes para "ser" y actuar en un mundo en el que el consumo y la apariencia se han perfilado como principios casi éticos. Se aclara, no obstante, que dichas subjetividades mediáticas no corresponden linealmente a las particularidades de los sujetos, pero sí marcan tendencias y orientaciones culturales bastante permeadas por las lógicas del mercado.

Palabras clave: infancia contemporánea; pedagogías de la cotidianidad; consumo; publicidad; género.
Recibido: 23-mayo-2016 / Aprobado: 27-marzo-2016

\begin{abstract}
This work aims to contribute to identify childhood female subjectivities that have been built through the production and circulation of texts in the magazine Tú — directed to girls between 9 and 18 years old-. It seeks to demonstrate how this type of cultural products are anchored in a pedagogy that exceeds the boundaries of the school and settles in the everyday life, in the familiarity of the lives of girls and adolescents, providing relating to "be" and act in a world in which the consumption and the appearance been outlined as principles almost ethical. It is clarified, however, that these media subjectivities do not correspond linearly to the particularities of the subjects, but they do mark tendencies and cultural orientations quite permeated by the logics of the market.
\end{abstract}

Keywords: contemporary childhood; everyday life pedagogies; consumption; advertising; gender.

\footnotetext{
* El presente texto es resultado de una indagación personal iniciada en 2014 y concluida en 2015, a propósito de la pregunta por estas otras pedagogías que, naturalizadas en el mundo cotidiano, contribuyen a afianzar ciertas éticas en torno "al cuidado de sí" en el mundo femenino.

1 Magíster en Estudios de Género, Universidad Nacional de Colombia. Profesora de la Universidad Distrital Francisco José de Caldas. Correo electrónico: ingriddelgadillo@gmail.com
} 


\section{Introducción}

La infancia como objeto de reflexión ha pasado de la idea de su muerte, como afirmaba Postman (1994), a la constatación de su transformación. De los niños obedientes, sumisos, "inocentes" se ha llegado a la noción de sujetos activos, partícipes, pequeños dioses domésticos (Bruckner, 2002) e incluso se les ha otorgado un grado importante en las categorizaciones como consumidores. Sin embargo, no existen suficientes estudios sobre cómo operan estas nuevas realidades y menos aún sobre qué tipo de dinámicas asumen los productos culturales en esta configuración.

Al respecto, en este texto se sostiene la tesis de que los modos de representación de la infancia e incluso de lo femenino, en algunos textos mediáticos, no conducen a la emancipación de los sujetos, sino que, por el contrario, llevan a profundizar las lógicas que las sociedades de control instalan colectivamente. Lo anterior no significa que los sujetos, en este caso las niñas y adolescentes, desde sus múltiples experiencias no construyan relaciones diversas con los medios y, desde allí, estrategias de resistencia, de respuesta o de distancia. Sin embargo, en este documento se destacan las formas sutiles como algunos medios intentan capturar las formas de ser mujeres desde temprana edad.

\section{Metodología}

En este sentido, interesa desde la perspectiva de análisis de contenido indagar en los materiales mencionados — vistos como representantes de una época- acerca de cómo contribuyen a pautar la feminidad infantil: no la infancia en general, sino aquella que supone una especificidad de género, lo femenino, pues es claro que nos constituimos en sujetos desde la adscripción cultural a uno u otro género a partir de nuestras marcas biológicas y desde allí conformamos particularidades, intereses, expectativas, hoy bastante aprovechadas por el mercado ${ }^{2}$.

El análisis de contenido que adelantamos en este trabajo retoma elementos generales de la propuesta

\footnotetext{
2 Esta adscripción cultural de género no supone la negación a la diversidad que encarna, ni a la posible transformación de referentes afectivos o identitarios.
}

metodológica de Roland Barthes, expresada en la recopilación de sus trabajos El sistema de la moda y otros escritos (2003b) y en especial en el ensayo de 1960 titulado "El azul está de moda este año". Notas sobre la investigación de las unidades significantes en el vestido de moda (Barthes, 2003a). De este ensayo retomamos la idea, mutatis mutandis, de que en las revistas de moda existe un significado que siempre es necesario restablecer, para nuestro caso la infancia (para Barthes: la moda) (2003b, p. 393).

La revista frecuentemente ofrece un léxico que, en términos de Barthes, puede ser "unívoco" o "absoluto", por cuanto presenta los signos como esencias inmóviles, como si fueran verdaderas, eternas, inmutables; estas atribuciones de carácter arbitrario se tornan en imposiciones por lo mismo (2003b, p. 387). También es posible que la revista abandone el léxico absoluto y permita oposiciones o variantes en donde esté presente la contradicción (2003b, p. 388). Serio, divertido; arriesgada, recatada; sé tú misma, sé diferente como, por ejemplo, lo presenta la Revista Tú.

Bajo estos supuestos, interesa identificar algunos de los rasgos que remiten virtualmente al significado infancia. Estos rasgos, como anota Barthes (2003b, p. 394), son modelos que no es necesario contabilizar en la medida que no responden al criterio de promedios. Por consiguiente, se establecen las relaciones entre distintos rasgos que es lo que hace significar; en esta investigación: la infancia. Desde lo señalado, el análisis de algunos números de la revista tendrá un carácter aleatorio, no porcentual, ni exhaustivo, pese a que el corpus de las revistas revisadas va de enero a diciembre de 2013.

\section{Perspectivas teóricas}

Subjetividades infantiles en contexto

Los procesos de subjetivación tienen que ver con los modos cómo ha sido nombrado lo humano y cómo han sido apropiadas las nominaciones en términos colectivos inconscientes, desde temporalidades de largo plazo y anclajes emotivos, corporales, conceptuales. Estos no son definibles solo por la interacción concreta y cotidiana, ni solo desde dinámicas y prácticas de impugnación y de autoelaboración, sino por la participación en tejidos culturales y sociales desde los cuales se construyen ideas, relatos de sí, de los otros. Los cuales pueden funcionar como conceptos acerca de qué o quién 
encarna lo humano, qué lo constituye, en el marco de procesos de larga y extensa duración (desterritorializados) (Guattari, 1996).

Cada época o de fractura histórica, según Guattari (1996), ha producido formas distintas de nombrar, de concebir a los seres humanos, su relación con el cosmos, con la Tierra, con los otros, con las máquinas. Estos aparatos colectivos de subjetivización, en "la era de la desterritorialización capitalista de los modos de conocimiento y técnica" (Guattari, 1996, p. 22), se caracterizan por entremezclar las técnicas de disciplinamiento y panópticas con aquellas técnicas de la biopolítica, que describió Foucault en su momento, en donde la vida y lo viviente serán integrados en los procesos de producción y reproducción capitalistas (Quijano, 2006).

Entre muchas otras transformaciones, Guattari hace énfasis en la subjetividad humana como una nueva clase de subjetividad "mecánica" que está en capacidad de procesar la densidad de información circulante y actuar en concordancia con estos procesos, lo cual es reforzado por "[...] una opresiva cultura de medios de comunicación de masas y una política infantil de consenso [...]" (1996, p. 25).

Los medios de comunicación de masas como nuevos educadores forman parte de esta nueva lógica social en donde los individuos ya no son números sino cifras en términos de "indicadores, datos, mercados o 'bancos'", en un capitalismo que ya no se ocupa de la producción, sino de la venta de servicios, del flujo del capital, de los mercados, pues "el departamento de ventas es el 'alma' de esta época y el instrumento de control social es el marketing" (Deleuze, 2006, p. 279).

Por su parte, Bauman (2007) argumenta que no se trata de sociedades de producción sino de consumidores, en donde el principal producto, posible incluso de la obsolescencia, es cada uno de nosotros.

[...] la característica más prominente de la sociedad de consumidores - por cuidadosamente que haya sido escondida o encubierta - es su capacidad de transformar a los consumidores en productos consumibles, o más bien de disolverlos en un mar de productos [...]. (p. 26)
La "subjetividad" de los consumidores está hecha de elecciones de consumo, elecciones tanto del sujeto como de potenciales compradores del sujeto en cuestión. Su descripción se parece a una lista de supermercado. Lo que supuestamente es la materialización de la verdad interior del yo no es otra cosa que una idealización de las huellas materiales - cosificadas - de sus elecciones a la hora de consumir (Bauman, 2007, p. 29).

La apuesta colectiva ha pasado de la búsqueda de la solidaridad, al logro del bienestar individual. Las mujeres participan de este sueño colectivo, en tanto ahora se declaran autosuficientes, independientes, autónomas. De igual forma, los niños y las niñas desde edades tempranas son expuestos a múltiples productos y lógicas de consumo, de manera que aprenden muy pronto a participar en ellas.

Los niños y las niñas al formar parte de los grupos sociales, al habitar esta temporalidad y espacialidad se integran a las dinámicas de las sociedades de control que funcionan — como anota Busteloa través de "redes de comunicación masiva flexibles y móviles que, por su carácter dinámico, se hacen más difíciles de develar" (2007, p. 60). Los niños, las niñas y los adolescentes no pueden leerse, como lo han planteado algunos autores (Buckingham, 2002) solo como audiencias activas, con criterios suficientes para significar autónomamente los mensajes de los medios y de la publicidad, quienes lograrían de manera soberana un distanciamiento de sus propuestas. Por el contrario, su subjetividad está significativamente interpelada por los medios de comunicación masiva, televisión, videojuegos ${ }^{3}$, espectáculos musicales, asistencia a lugares de entretenimiento, entre los que se cuentan los centros comerciales.

Juliet Schor (2006), denunciaba hace una década las alianzas que las industrias y los anunciantes han establecido con los niños y las niñas,

\footnotetext{
3 El Departamento Administrativo Nacional de Estadística (Dane) en marzo de 2009 entregó el informe sobre consumo cultural en Colombia. Encuesta realizada a 38237 personas, en 12031 hogares de 68 municipios de 26 departamentos. En este se destaca que el uso del tiempo libre está concentrado en un $71 \%$ en ver televisión; el $96,17 \%$ de los niños entre 5 y 12 años ven televisión. El 95,20\% de los mayores de 12 años ven televisión y el $76 \%$ oyen radio. En cuanto a los videojuegos, el 40,91\% de los niños entre 5 y 11 años los practica (Dane, 2009).
} 
ingresando tanto a los espacios privados familiares como a las escuelas a través de estudios de mercadeo, etnografías del consumo e incluso contratando a los mismos niños o niñas para que publiciten algún producto o indaguen sobre los gustos de los demás a través de técnicas como la del "boca-oreja entre amigas". Las estrategias para seducir al público infantil e incluso adulto, o para conocer de sus gustos, van desde involucrar a niñas y jóvenes a redes online para que descubran los secretos de sus amigas y los entreguen celadamente a las compañías:

La empresa asegura que todas sus agentes establecen contacto con una media de 512 niñas en prácticamente todas las áreas de la vida cotidiana —en la clase de inglés, en los partidos de fútbol, en los trayectos compartidos en coche, incluso en el club hípico- Con su red cada vez más extendida, la empresa estima que se puede llegar a 20 millones de niñas de todo el país. (Schor, 2006, p.106)

O a partir de generar identidad con los productos o las marcas, como explicó Camilo Herrera, presidente de Raddar ${ }^{4}$ en Colombia, en una conferencia en 2010 sobre "El poder de las marcas":

[l]a marca tiene un vínculo emocional de identidad con el consumidor que en muchos casos lo define como parte de una comunidad y que el vínculo emocional de una marca queda impreso en el consumidor cuando ésta le ha satisfecho su promesa al punto de poder recomendarla. (Herrera, 2010).

Algunos autores, como David Buckingham (2002), afirman que en las últimas décadas ha aumentado de manera notable el consumo, la variedad de productos y las facilidades creadas para favorecer las compras. Esto ha contribuido al incremento del consumo casi al mismo nivel que la actividad de mirar televisión en tiempos de ocio por parte de los niños y las niñas, como

\footnotetext{
2 Raddar es un grupo que se interesa por comprender las condiciones y lógicas del mercado para recomendar acciones a sus clientes. En sus propias palabras, Raddar se define como "un grupo empresarial, de capital mayoritariamente colombiano, que dedica sus esfuerzos a la comprensión del mercado, del consumidor y de los ciudadanos" (Raddar, s.f.).
}

lo evidenció el citado estudio del Dane (2009). Buckingham afirma que los cambios en la composición familiar, el aumento relativo del poder adquisitivo y "la 'valorización' simbólica de la infancia, ha supuesto una mayor influencia de los pequeños sobre el consumo y las compras familiares" (2002, p. 165), a partir de reconocer que la infancia en esta época es un referente central de afecto y protección.

De igual modo, los mercados dirigen su atención hacia los niños y las niñas, los constituyen en un marketing de nichos importante. Los medios han ampliado los canales y los programas para niños sin que importe la calidad. Los niños se han instituido como importantes objetivos de este mercado. En estos espacios abunda la diversidad, pero los criterios son más comerciales que de calidad, así mismo, se ha desdibujado la diferencia entre educación y entretenimiento, ya no es clara la intencionalidad de los productores "[...] todos los textos mediáticos, se podrían entender efectivamente como anuncios de otros textos mediáticos" (Buckingham, 2002, p. 166). En esta dinámica, sin embargo, se amplía la distancia entre niños ricos y niños pobres en información.

Las revistas y la producción de subjetividades Los análisis sobre textos públicos (revistas, programas de televisión, juegos interactivos, etc.) se centran en el papel de las empresas comerciales como nuevas educadoras, como nuevos sitios de aprendizaje y como causas de la crisis de la infancia, desde la perspectiva de asumir la educación como un proceso que no solo se da en las escuelas, sino que existen otros escenarios que contribuyen y de manera poderosa a educar. Esta "otra educación" es denominada

Pedagogía cultural, que se remite a la idea de que la educación tiene lugar en diversos sitios sociales que incluyen la escolarización, pero no se limitan a ella. Los lugares pedagógicos son aquellos donde el poder se organiza y despliega, incluidas las bibliotecas, la televisión, las películas, los periódicos, las revistas, los juguetes, los anuncios, los juegos de vídeo, los libros, los deportes. (Steinberg y Kincheloe, 2000, p. 17)

Sin embargo, la pedagogía cultural, dominada hoy por la producción mediática y mercantil con 
apoyo de la publicidad, no ha surgido solo hasta ahora, sino que desde hace siglos funciona como elemento de formación de los sujetos sociales. Es así como Norbert Elias (1979), al realizar el análisis de textos sobre la Civilité en Francia, fundamentalmente da cuenta de la transformación de hábitos y modos de comportamiento y de sensibilidad desde el siglo XVI. Distintos manuales, textos de urbanidad e incluso revistas han circulado como soporte de formas específicas de comportamiento y sensibilidad social.

En este sentido, se asume que el espacio escolar no es el único escenario que forma o que ha formado, y en muchos casos es el que menos se ocupa de ofrecer pistas para ubicar a los sujetos en el campo de lo social, no así en lo laboral. Por el contrario, los cuentos, los manuales, las revistas, como materiales de entretenimiento asimismo constituyen insumos importantes en la constitución de subjetividades, en tanto aportan saberes de orden práctico, posicionan individuos, "verdades", trazan directrices sobre comportamientos adecuados y/o deseables, ofrecen alternativas de acción en determinados momentos, entre otras.

Para el caso, desde la década de 1930 circuló en Colombia un manual ilustrado denominado Cartilla moderna de urbanidad para niñas con un alto número de ediciones ${ }^{5}$ en donde se indicaban las normas básicas sobre las características que se debían cumplir para ser una "niña bien educada". Entre los comportamientos que se prescribían, se indicaba la aceptación sumisa de lugares, alimentos, repulsas, regaños, así como las molestias o burlas de otras para con ella. Se exigía que se apartara de malas "ocasiones" o de las malas compañías, de niñas "casquivanas", e irrespetuosas, curiosas, conversadoras, risueñas y juguetonas. Por el contrario, en la calle debía tomar el camino más recto, sin entretenerse, ni jugar; debía saludar y auxiliar a los que lo necesitaran. Se hace énfasis especial en el aseo y la presentación personal "[...] conviene lavarse y peinarse siempre que sea necesario para estar rigurosamente limpia" (FTD. 1966, p. 6).

\footnotetext{
Se revisó la décima tercera edición del año 1966.
}

Estas prescripciones se anclan en la perspectiva disciplinaria en cuanto configuran cuerpos dóciles, sumisos, atrapados en el orden de la moralidad cristiana, caritativa y temerosa. Del mismo modo, estas directrices se inscriben en el dispositivo de la sexualidad, que desde la biopolítica se diseñó en función de la gestión sobre el cuerpo y la sexualidad fundamentalmente femenina e infantil, que produce figuras como "la mujer nerviosa, la esposa frígida, la madre indiferente o asaltada por obsesiones criminales, el marido impotente, sádico, perverso, la hija histérica o neurasténica, el niño precoz y ya agotado, el joven homosexual que rechaza el matrimonio o descuida a su mujer" [...]" (Foucault, 1991, p.135).

Los cuerpos infantiles femeninos también fueron objeto de este dispositivo que, como hemos visto, los pretende rígidos, obedientes, particularmente sometidos a la mirada, a la autoridad y al deseo de los otros: "deja el juego en cuanto se lo mandan" (FTD, 1966, p. 22),

¿A quién hemos de obedecer más particularmente? 317

A nuestros padres y maestros porque es una obligación muy sagrada [...]

¿Qué hay que pensar de la niña díscola y desobediente?

Que, si no trabaja para corregirse de un defecto tan grave, será mala cristiana, muy desgraciada durante toda la vida, según prueba la experiencia.

¿En qué se conoce la docilidad de una niña?

[...] (p. 48)

Según Szir, en un análisis de textos escolares de principios y mediados del siglo XX en Argentina,

- Hay muchos elementos que sorprenden: la manera de dirigirse a los lectores, el tipo de mensajes didácticos que apelan en forma reiterada a la patria, la familia, a Dios, cierto carácter represivo en lo que se refiere a las conductas del niño hacia los demás. Otro elemento que se destaca son las diferencias de género, el rol tan marcado de la mujer en relación con el hogar y la educación de los hijos. Pero, por otra parte, son impresos visualmente muy atractivos, con imágenes muy cuidadas y siempre presentes. (2007) 
Szir (2012) también señala que la relación de niños y niñas con los medios se ha venido transformando en distintas épocas según los avances de la tecnología; de la imagen impresa se ha pasado a la televisiva, luego a la masificación del cine para después pasar a la digital, incidiendo en el consumo de imágenes que ahora se acompañan de otros lenguajes, música, velocidad, palabras, etc.

Ahora bien, en relación con los estudios adelantados alrededor de las revistas femeninas y la construcción de la subjetividad de género, en términos generales, ha existido la tendencia a satanizar sus contenidos, identificando las temáticas con discursos machistas, de corte patriarcal, en donde las mujeres son asumidas como objetos sexuales, pasivos y consumistas (Carrington y Bennett, 1999).

Angela McRobbie (1998) al revisar planteamientos como los anteriores, muestra cómo las revistas para "chicas y mujeres" no están escritas solo desde la perspectiva de una feminidad tradicional, sino que procuran provocar fisuras a esta. Así mismo, da

318 cuenta de algunas discusiones al respecto de esta mirada unilateral de las revistas, mostrando cómo no es posible hacer juicios, generalizar la lectura o desdeñar el valor que las mujeres les conceden para elaborar una mirada distinta y no subordinada de la feminidad.

En el análisis sobre los contenidos de las revistas para "chicas y mujeres", McRobbie dice que "se trata de un discurso complejo que declara la muerte de la ingenuidad" (1998, p. 289), lo cual las prepara para explorar con mayor libertad el placer y el goce.

Carrington y Benett (1999), aún más radicales que McRobbie en el análisis del papel favorable e interactivo de las revistas, plantean, a su vez, que estas retoman temas y relaciones que han sido considerados como tabú, así como posicionan otros que ya están instalados en la cotidianidad social de las mujeres tales como la homosexualidad, el conocimiento sobre el sexo y la protección ante este, el cuidado del cuerpo, etc. De igual modo, explicitan el carácter pedagógico de las revistas, pues dicen que estas se ubican en un lugar de autoridad, como expertas que conocen la verdad, especialmente, sobre el sexo; las revistas se constituyen en manuales pues aportan información puntual y específica sobre lo que debe y no debe hacerse y sobre: "Cómo besar", "Cómo coger a tu chico", "Cómo decir si estás bien en la cama" y "no hagas nunca"(Carrington y Benett, 1999, p. 156).

A su vez, Valerie Walkerdine (1998) indica que ni los estudios feministas, ni los estudios culturales o de historia cultural han hecho investigaciones serias alrededor de los niños pequeños, menos aún de las niñas y de su sexualidad. Esta autora mediante el estudio de algunos productos de la cultura popular como la música y algunas series televisivas observa cómo se da un fenómeno de erotización de las niñas, en el que el imaginario de ingenuidad se cuestiona, en tanto ese proceso se encuentra articulado a las fantasías socioculturales y adultas.

Estos distintos abordajes exigen una aclaración frente a la pregunta acerca de la "influencia" que pueden o no tener los productos culturales, emanados de las industrias televisivas o publicitarias, en los sujetos y la sociedad. Al respecto, asumimos que los productos culturales son generados en el seno de una época, pero que estos productos mediante un proceso de retroalimentación dan fuerza y contribuyen en la consolidación de aquello que se está cristalizando social y culturalmente. Desde esta perspectiva, nos separamos de la tesis mecanicista que pretende ubicar a los sujetos como consumidores absolutamente pasivos, frente a los medios y productos culturales en general. Tampoco los consideramos plenamente autónomos, racionales y reflexivos cuando se trata de interactuar con un conjunto de elementos que constituyen una época particular.

Lo anterior nos permite afirmar que la creación de significados frente a los distintos artefactos culturales con los cuales los sujetos, en nuestro caso las niñas, interactúan, si bien están atravesados por condiciones de clase, raza, grupo social, historias personales y familiares, así como imágenes de lo femenino, expectativas de futuro, etc., no pueden ser leídos o interpretados por fuera de un marco social de producción de sentido, en el que participan como miembros de un colectivo medianamente cohesionado.

A propósito de estos planteamientos, se reconoce que, desde el campo de los estudios culturales, se ha hecho énfasis en cómo los sujetos leen 
y significan los elementos que circulan desde los ámbitos mediáticos (Morley, 1996). Sin embargo, no hay suficientes estudios a propósito de los productos culturales que se disponen para los niños y menos aún para las niñas (Carli, 2014).

\section{Algunos hallazgos}

Porque nadie es como Tú

La Revista Tú. Porque nadie es como Tú es editada y distribuida por el grupo Editorial Televisa Colombia Cultural S.A., mediante convenio con el grupo Editorial Televisa México ${ }^{6}$. La publicación es muy popular en países de Hispanoamérica como México, Colombia, República Dominicana, Puerto Rico, Venezuela, Chile, Ecuador, Perú y Argentina, así como para la población latina en Estados Unidos. La revista se publicó por primera vez en 1979 (Mercado Valencia, 2009).

Esta revista es definida por sus editores como:

Tú, es el medio ideal para impactar a las adolescentes porque durante años ha sido compañía perfecta, pues las apoya en la definición de su propio estilo y personalidad en esta importante etapa de su vida. [...] Es amiga cómplice de sus lectoras, en cada número las ayuda a entender sus cambios físicos y emocionales, a resolver problemas con sus padres y a soportar la presión de su grupo social. (Televisa, 2014).

El grupo objetivo que reconocen es el de adolescentes entre 9 y 18 años. El nivel socioeconómico al que se dirige es "medio, medio-alto, alto" y su periodicidad es mensual (Televisa, 2014). Según la página consultada, la composición temática editorial se distribuye de la siguiente manera: belleza 17\%; espectáculos 12\%; moda 15\%; psicología 25\%; participación de lectoras 19\%; y tecnología 12\%.

La vida de las adolescentes y jóvenes a quienes va dirigida la revista es, de cierta forma,

\footnotetext{
6 "El Grupo Televisa es una compañía privada mexicana de medios de comunicación, la más grande en el mundo de habla hispana con base en capitalización de mercado, y es uno de los principales participantes en el negocio de entretenimiento a nivel mundial [...]. Por su parte, Editorial Televisa es la compañía editora de revistas en español más grande a nivel mundial y líder en Latinoamérica y en el mercado hispano de Estados Unidos". (Mercado Valencia, 2009)
}

sintetizada en estas dimensiones, en donde, la probable tristeza, las preguntas sobre el amor, la personalidad y la belleza son temas que se tornan familiares, en tanto afectan a famosos y a lectoras en general. La separación de una pareja reconocida en la farándula, los noviazgos, los embarazos, la moda, las noticias de sus vidas personales, sus signos zodiacales, entre otros, se entretejen con la cotidianidad del público que consume la revista, logrando cercanía, idealización, empatía e incluso antipatía, según los casos y la preferencia de la revista.

Estos temas se visibilizan en las portadas de los números que circularon en 2013, de los cuales solo retomaremos algunos en la tabla 1.

Como se viene señalando, en los temas que se destacan en las portadas, el énfasis está puesto en las acciones de los "famosos". Se anuncian regalos del tipo afiches o imágenes de personajes de farándula, temas asociados con el amor y la conquista, test de personalidad y pistas para alcanzar la fama, la pareja como símbolo de bienestar y plenitud.

Estos planteamientos, siguiendo a Bauman (2007), se inscriben en la propuesta de hacer de los consumidores productos consumibles - como se mencionó-, a través de la creación de un programa de vida y una escala de valores que se articulan a una estética, a la idea de configurar un estilo, un modo de ser, actuar, parecer, sentir, que los "educadores" mediáticos contribuyen a moldear. Las pretensiones formativas de instituciones como la familia y la escuela quedan enormemente desvirtuadas en el marco de estas afirmaciones, ya que, como amiga cómplice, la revista aborda temas innombrables en estos entornos educativos, no hace juicios ni exigencias, tolera y promueve distintos estilos, "comprende" a las adolescentes y las invita a tomar riesgos; como cómplice comparte los excesos, los secretos, entre otros, pues la escuela y en general la familia no están preparadas para asumir los temas que actualmente conforman la vida de las adolescentes.

En cuanto a las prescripciones que estos manuales de instrucción contemporánea plantean, retomamos algunos apartados que permiten entrever qué tipo de subjetividades femeninas se configuran y cuáles son los preceptos que estas demandan. 
Tabla 1. Portadas de la Revista Tú en 2013.

\begin{tabular}{|c|c|c|c|}
\hline Enero & Mayo & Septiembre & Diciembre \\
\hline $\begin{array}{c}\text { Año nuevo, nueva Miley ¡inicia estre- } \\
\text { nando peli!// } \\
\text { Predicciones } 2013 \text { tu signo mes por mes// } \\
\text { Justin, Kate y OneDirection te dan conse- } \\
\text { jos de belleza// } \\
\text { Haz las paces / tu novio y tus BF (Best- } \\
\text { Friend)// } \\
\text { Cita virtual ¿lista para conocer a tu "face- } \\
\text { friend"?// } \\
\text { Ralph el demoledor te encantará// } \\
\text { Entrevista: María Gabriel debuta en el } \\
\text { cine// } \\
\text { ¿Títere de tu estado de ánimo? Descú- } \\
\text { brelo// } \\
\text { Oráculo del amor ¡consúltalo!// } \\
\text { Moda florece en vacaciones// } \\
\text { Duina del Mar una propuesta 100\% tal- } \\
\text { ento colombiano// }\end{array}$ & $\begin{array}{c}12 \text { cosas que ellos odian } \\
\text { y adoran de las chicas// } \\
\text { ¿A qué pareja famosa se } \\
\text { parece tu relación? // } \\
\text { Feng Shui para atraer el } \\
\text { amor// } \\
\text { No me acostumbro a la } \\
\text { fama: Lucy Hale// } \\
\text { Lindísima: elige el volu- } \\
\text { men de tu maquillaje// } \\
\text { Supertest ¿Tu BFF quiere } \\
\text { algo contigo? ¿Te ama } \\
\text { tanto como tú a él? // } \\
\text { OneDirection y las som- } \\
\text { bras de sus ex// } \\
\text { Noviazgos peligrosos: } \\
\text { detecta a los patanes// }\end{array}$ & $\begin{array}{c}\text { Tercera entrega 1d espe- } \\
\text { cial (OneDirection) // } \\
\text { Descifra su lenguaje se- } \\
\text { creto, conquístalo según } \\
\text { el signo// } \\
\text { Día de amor y amistad: } \\
\text { ¿soltera? Deja el drama } \\
\text { ¡Festeja! // } \\
\text { Conócelo con solo decirle } \\
\quad \text { Hola// } \\
\text { Detalles de amor igratis! } \\
\text { que el amará// } \\
\text { Labios que enamoran } \\
\text { maquillaje para conquis- } \\
\text { tarlo// } \\
\text { 10 ideas Cute para la } \\
\text { primera cita// } \\
\text { BIG TIME RUSH ¡Los } \\
\text { amamos! } 24 / \text { seven// }\end{array}$ & $\begin{array}{c}\text { Adornos y tips para } \\
\text { esta navidad// } \\
\text { No más propósitos, } \\
\text { renuévate desde } \\
\text { hoy// } \\
\text { Lo in y lo out, re- } \\
\text { sumen del año// } \\
\text { Concierto JB un } \\
\text { sueño cumplido// } \\
\text { Austin Mahone } \\
\text { la revelación del } \\
2013 / / \\
\text { Deseos de belleza } \\
\text { para lucir hermosa// } \\
\text { Hechizos para to- } \\
\text { das// } \\
\text { ¡Magia para el } \\
2014 \text { ! // }\end{array}$ \\
\hline
\end{tabular}

Fuente: elaboración propia.

Si en la década de 1950 e incluso 1960 la moralidad exigía niñas virtuosas, no juguetonas ni risueñas más allá de lo permitido por los adultos, las pedagogías contemporáneas de la mano del mercado instruyen sobre el ideal de niña-mujer que puede ser, mediante distintos relatos, que van desde un listado de tips para no aburrir a un chico, hasta qué debes usar y cómo debes actuar. Algunos ejemplos permiten ilustrar lo expuesto:

Acerca de los "tips para no aburrir a un chico":

Además de verte linda, demuestra tu inteligencia y búscate varios temas de conversación 2. Déjalo con ganas de ti; es decir, siempre sé la primera en despedirte 3. De vez en cuando, olvídate de él por un día. ¡Desaparécete! 4. Haz que tus citas sean divertidas y relajadas 5. Jamás caigan en la rutina. (Revista Tú, 2013f, p. 9)

Sobre cómo ser atrevida y libre:

Si quieres ser una chica muy activa, vivir al límite y disfrutar de libertad sin que nada te detenga, necesitas empezar a usar tampones. (Revista Tú, 2013d, p. 40).

El cuento de las princesas aún sobrevive, pero de carácter "real", independiente y autónoma que se proclama en esta época para cualquier tipo de individuo.

Princesitis... las princesas se escaparon de los cuentos. La princesa real se esfuerza por conseguir lo que quiere y no llora para que le ayuden". (Revista Tú, 2013c, pp. 80-81)

La condición de sujeto independiente, activo, deseable, con dominio de sí, está presente en estos tips para conquistar, para no aburrir. No obstante, la contracara de la apuesta se halla en que se construye una subjetividad precisamente para otros, en función de ser amada, atraer, ser valorada, siempre en función de la mirada del otro.

Esta relación estrecha entre la identidad y la mirada del otro que construyen las mujeres es, de acuerdo con Castellanos (1996), parte de las 
lógicas de socialización a través de las cuales las mujeres son formadas, tanto desde las prácticas disciplinarias propias de la escuela, que contribuyen a docilizar los cuerpos a partir de otras técnicas que moldean y modulan no solo los cuerpos sino también sus movimientos, su apariencia, sus tácticas incluso de seducción, pues: "[...] el cuerpo se instala como el primer registro de identidad femenina [...] para lo cual se deben producir ciertas tallas, gestos, posturas, buscando que el cuerpo femenino se configure como una superficie ornamentada" (Bartky, citada por Castellanos, 1996, p. 34).

Desde estos procesos de docilización y moldeamiento corporal se produce lo que Bartky denomina "un panóptico interiorizado" que sugiere la preocupación por la apariencia, la necesidad de reconocimiento, el interés en la imagen que se proyecta en los otros como parte de las principales inquietudes de la mayoría de las mujeres, evidenciadas en la fascinación por el espejo, por el maquiIlaje, por el adorno, como dice esta autora (Bartky citada por Castellanos, 1996, p. 36).

La revista conoce esta necesidad y no solo aporta tips de belleza, de cuidado corporal, facial, del cabello, entre otros, sino que precisa las cualidades que se deben tener para ser "triunfadora y feliz" del tipo "las veinte maneras más efectivas de cautivar" (Revista Tú, 2013a, pp.76-77) o "las doce cosas que ellos odian y adoran de las chicas (Revista Tú, 2013b, pp.70-71) o "cómo llegar a ellos sin asustarlos. Tips básicos" (Revista Tú, 2013b, pp. 66-67).

Esta "subjetividad" anclada en el supuesto de ser mirada, aceptada, se entreteje muy bien con la de los consumidores, pues está hecha de elecciones de consumo para lograr la apariencia deseada, para capturar la atención, sobre lo cual como se señaló atrás, la verdad sobre quienes somos se define a partir de lo que es plausible y posible adquirir como en "una lista de supermercado" Bauman (2007, p. 29). En la revista se destacan los implementos para configurar este sujeto femenino contemporáneo, que está hecho de colores, de fragmentos, ojos, boca, piel, accesorios:

Estilo primaveral. Para satisfacer el gusto de las más glamorosas $[\ldots]$
Rostro de película. Cuida tu piel de los rayos del sol con el bloqueador [...]

Mirada impactante. Si buscas una mirada intensa maquíllate como las estrellas de cine con la tendencia $[\ldots]$ y utiliza productos...

Regreso divertido vuelve al colegio con los accesorios más cool para esta temporada. Diseños de [...] en el Centro Comercial [...]. (Revista Tú, 2013a, pp. 2-4)

La apuesta colectiva ha pasado de la búsqueda de la solidaridad al logro del bienestar individual. Las mujeres participan de este sueño colectivo, en tanto ahora se declaran autosuficientes, independientes, autónomas. Siguiendo a Bauman, las mujeres se han apropiado del modelo de cowboy norteamericano, solitario y libre de vínculos, y ahora son las cowgirls modernas, para quienes la responsabilidad es consigo mismas (2007, pp.74-75). El ideal del yo para niñas y adolescentes se expresa en este texto de la Revista Tú que invita a "ser" de manera ambigua, por un lado, a través del imperativo de la conquista y por el otro, a partir de la autoafirmación, la defensa de la personalidad, la condición de princesa, pero ¡valiente!

10 PASOS PARA CONQUISTAR. [...] una niña que se ama a si misma (no una ególatra) se convierte automáticamente en una princesa, atractiva, valiente y capaz de atraer el amor de cualquier chico, sin necesidad de modificar su personalidad o de andar rogando. (Revista Tú, 2013g, pp.72-73)

Incluso, se aportan reglas, destacando una moralidad responsable y "madura", en donde la revista asume una posición de adultez, que con tono maternal y suplicante increpa a las niñas para que "hagan sus deberes" y se comporten "bien", no porque se reivindiquen principios, sino con un interés, como acciones que permitirán alcanzar algo que se quiere, en este caso, son medios para lograr la autorización de los padres para tener un noviazgo

10 CLAVES PARA QUE TE DEJEN TENER NOVIO. [...] Demuestra tu madurez ¿Quieres evidenciar que eres una niña capaz de cuidarte y tomar decisiones? ¡Manifiéstalo! Empieza por cumplir lo que le 
prometes a tus padres: llegar temprano, arreglar tu cuarto, bañar al perro, y todas las obligaciones que tienes en casa, así les harás saber que tienes bajo control diferentes áreas de tu vida, y podrás incluso con la responsabilidad de tener novio [...] Te lo diremos hasta el cansancio: cumple con tus deberes y pórtate bien. Deja de pelear con tus hermanos. Por piedad tiende tu cama y arregla tu ropa. (Revista Tú, 2013e, pp. 63-64)

Desde edades tempranas para las niñas, se despliega la propuesta de la sociedad de consumidores pues son expuestas a múltiples productos y lógicas de consumo, de manera que aprenden muy pronto a participar en ellas

Uno de los puntos centrales de la formación de las personas y de los valores morales de la vida contemporánea consiste en la familiarización de los niños con los materiales, medios de comunicación, imágenes y significados propios, referidos o relacionados con el mundo del comercio. (Cook citado por Bauman, 2007, p. 80).

Un ejemplo de este tipo de planteamientos lo podemos rastrear en la siguiente publicidad de la Revista Tú, que invita a los niños a "ser muy naturales" mediante el discurso de la reutilización, la flora, la fauna, reivindicando el vínculo con la naturaleza, apelando incluso al estereotipo de lo "tribal", en un acercamiento a lo que llamaríamos lo ecológico, pero con un contenido de fondo totalmente mercantil:

Colloky presenta su colección Verano 2013 que invita a los niños a un mundo fantástico de flora y fauna; donde se mezclan la aventura, los ritmos tribales y la innovación de reutilizar elementos para convertirlos en prendas únicas. La novedosa colección se caracteriza por el uso de colores vibrantes con toques modernos y sofisticados, que rescatan el vínculo entre los niños y la naturaleza. (Revista Tú, 2013c, p. 8)

\footnotetext{
7 Los resaltados en negrilla son del original.
}

En últimas, las niñas al formar parte de los grupos sociales, al estar inscritas en esta época, habitan esta temporalidad y espacialidad que las integra plenamente en las dinámicas del consumo. La mayoría de los niños, en general, así como un alto porcentaje de adultos están sumidos en las Ilamadas sociedades de control que funcionan, como anota Bustelo, a través de "redes de comunicación masiva flexibles y móviles que, por su carácter dinámico, se hacen más difíciles de develar" (2007, p. 60). Como se evidencia en estas notas que publicitan un estilo más allá de nociones de orden y arreglo o del tiempo.

Indie. Ese look que tienes recién te levantas está chic... ¿ ipuedes creerlo? En las pasarelas del desfile de Mercedes Benz de Nueva York, como la del diseñador Peter Som, las modelos impusieron estilo... (Revista Tú, 2013d, p. 16).

OLD FASHION. Esta temporada regresan las pañoletas y turbantes como en los años 70, así lo imponen las modelos de Marc Jacobs [...]. (Revista Tú, 2013d, p. 17)

En la franja de las Ilamadas Tweens, de las preadolescentes, presenta la sexualidad, la conquista, la noción de conservación y permanencia amorosa como vivencias indispensables para "ser" —en términos sociales - exitosa. Así mismo, la insistencia en la moda, en el estilo, en el maquillaje y en la apariencia física no implica posturas de autonomía, de reconocimiento, de libertad en la definición de un sujeto autoafirmado, sino seguramente lo contrario, la dependencia de aquello que se impone vía el estereotipo fashion europeo y/o norteamericano, inscrito en criterios de clase, individualizantes y ególatras.

Los textos de las revistas, a pesar de sus pretensiones de diversión y acompañamiento a niñas y adolescentes, se inscriben en estrategias publicitarias, en donde estas son leídas como potenciales consumidoras, ya no son solo "ciudadanos a formar", sino clientes en medio de las Ilamadas "sociedades de control". Según Bustelo (2007), los medios de comunicación contribuyen en esta dirección mediante los mensajes que circulan a través de las tecnologías: 
[...] configuran la subjetividad de la infancia, los intereses y los valores socialmente significativos así como los códigos para entender el mundo y, sobre todo, para conocer cómo ingresar y permanecer en el orden capitalista, que se mimetiza con la infancia al representarse como "el" mundo para niños, niñas y adolescentes. (Bustelo, 2007, p. 86)

A su vez, Minzi (2006) desde un estudio que adelantó sobre las representaciones de infancia que el mercado de productos para niños construye, afirma que la publicidad contribuye a promover algunas imágenes, en detrimento de otras, otorgando un carácter "natural" 8 a la superabundancia de imágenes y objetos que circulan no solo para la población infantil, sino también adulta, ya que la recepción de la publicidad es en muchos casos familiar. "Se trata de un poder simbólico que asentado en la uniformidad de los mensajes, solapa convenciones socio-históricas y las des-problematizan" (p. 213).

Las revistas, entre otros múltiples productos culturales, ubican a las niñas en una realidad marcada por el "estilo", la estética vestimentaria dominada por la moda, la competencia por la belleza, por el cuidado de la forma, casi ignorando lo que décadas atrás era un imperativo centrado en los otros, en la niña servicial, colaboradora, pasiva y prudente. En la actualidad, asistimos a una imagen de niña "adulta" que selecciona desde los atuendos cotidianos, el tipo de maquillaje, los tips de belleza: "lindísima: elige el volumen de tu maquillaje", "labios que enamoran", "maquillaje para conquistarlo", "monstruosamente linda", "looks para Halloween", "etiquetas cool back to school", hasta "los 8 besos que debes dar antes de los 18" o "ilas 15 actitudes que debes seguir para conquistarlo!" (Revista Tú, 2013).

\section{Algunas reflexiones adicionales}

La bipolítica en la modernidad operó sobre los cuerpos femeninos procesos de control de su sexualidad, vía la higiene, la salubridad, la moralización,

\footnotetext{
8 Para Minzi, basada en las ideas de Lins Ribeiro, la naturalización no está definida como legitimado, ni aprobado, sino como el reconocimiento, la aceptación de ciertas pautas sociales como "constitutivas de una 'normalidad", como la esencia de las cosas, no históricas, ni sociales.
}

la familia. Actualmente, la biopolítica ya no tiene como fin la productividad en términos de trabajo, por el contrario, su mandato es el consumo, la exaltación de la individualidad, de lo particular, del yo, como principios de existencia plena. Para Bauman (2007), el secreto mejor guardado es que cada uno es el objeto por ofrecer, a promocionar, a vender. Las niñas y las adolescentes aprenden bien este mandato en medio de sus espacios familiares, por supuesto, mediante la interacción en un medio en que todos estamos instados a comprar para ser, pero las otras pedagogías, de la vida cotidiana conforman una importante plataforma sobre la cual impulsar o profundizar aún más lo que ya circula y se impone culturalmente.

Indagar sobre estos procesos de construcción de las subjetividades nos ponen sobre aviso, pues nos encontramos en una época de crisis en donde los valores de corte patriarcal, dominador, explotador de la naturaleza, de la tierra y de su correlato femenino están Ilevando a un caos ambiental sin precedentes para la vida humana, y este tipo de construcciones culturales forman parte de una lógica de expoliación y desastre ambiental y social. Tales apuestas publicitarias, de juegos supuestamente inocentes, coloridos y alegres, están en la base de la perspectiva patriarcal del mundo y de la vida, en tanto priman los principios de la acumulación, de la apariencia, del goce pleno e individual, como principios para ser, por encima de posturas solidarias, de responsabilidad compartida, de protección y cuidado amoroso hacia las distintas formas de vida que existen.

La perspectiva de la filiación se quiebra en este tipo de productos culturales, pues en sus propuestas exaltan la individualidad — como se mencionó-, destacan un yo autónomo y soberano, que no necesita de los otros para ser, ni para construir un mundo en equilibrio, sin excesos, ni expoliación de pueblos, campos y mares. Para cumplir con los preceptos de estos textos mediáticos o gráficos solo se necesita un principio: la capacidad de consumo, por encima de la cualidad del compartir y del construir junto con los otros.

Las nociones de amabilidad y de amor que destacan Boff y Valverde (2002) como principios de un cuidado fraternal y solidario desde lo colectivo, 
en los productos culturales considerados, se inscriben sobre todo en la idea del goce personal, de un amor romanticón y edulcorado, en donde los sujetos pueden ser intercambiados fácilmente y si bien consideran el afecto como un requisito importante para la felicidad, es un amor de apego, de propiedades, de exclusividad de las parejas y no está dispuesto para ser compartido en otras esferas de la vida social, más que en los círculos cercanos y privados.

La crisis que vivimos no es, entonces, solo de tipo ambiental, político o económico, sino que es del orden de la ética, del cómo habitamos este mundo y cómo nos relacionamos entre nosotros como seres humanos y como parte del planeta. Carecemos de una mirada de mundo plena en la cual nos comprendamos como parte de un colectivo con responsabilidades compartidas.

Frente a lo anterior, la educación debe desempeñar un papel fundamental, pues es uno de los espacios que permite cuestionar esta crisis ética que caracteriza nuestra época, favorecer una mirada más compleja de lo que son los niños, las niñas, los sujetos y abonar el camino para un despertar nuevo, vital y espiritual de la conciencia y el pensamiento.

\section{Referencias}

Barthes, R. (2003a). "El azul está de moda este año". Notas sobre la investigación de las unidades significantes en el vestido de moda. En: El sistema de la moda y otros escritos (pp. 379395). Barcelona: Paidós.

. (2003b). El sistema de la moda y otros escritos Barcelona: Paidós.

Bauman, Z. (2007). Vida de consumo. México: Fondo de Cultura Económica.

Boff, L.; Valverde, J. (2002). El cuidado esencial: ética de lo humano, compasión por la Tierra. Madrid: Trotta.

Bruckner, P. (2002). La tentación de la inocencia. $4^{\text {a }}$ ed. Barcelona: Anagrama.

Buckingham, D. (2002). Crecer en la era de los medios electrónicos. Tras la muerte de la infancia. Madrid: Morata.

Bustelo, E. (2007). El recreo de la infancia. Argumentos para otro comienzo. Buenos Aires: Siglo xxı.
Carli, S. (2014). La cuestión de la infancia en América Latina: tiempo pasado, tiempo presente. Los dilemas de la educación contemporánea. En: Pensar las infancias: realidades y utopías. Bogotá: Ecoe Ediciones, Pontificia Universidad Javeriana.

Carrington, K.; Bennett, A. (1999). Las "revistas de chicas" y la formación pedagógica de la chica. En: Feminismos y pedagogías de la vida cotidiana. Madrid: Morata.

Castellanos, G. (1996). Género, poder y posmodernidad: hacia un feminismo de la solidaridad. En: L. G. Luna y M. Vilanova (comp.), Desde las orillas de la política. Género y poder en América Latina. Barcelona: Edición del Seminario Interdisciplinar Mujeres y Sociedad.

Deleuze, G. (2006). Post-scriptum sobre las sociedades de control. Polis, 13. Recuperado de: URL:http://polis.revues.org/5509

Departamento Administrativo Nacional de Estadística (DANE). (2009). Encuesta de consumo cultural. Recuperado de: http://www.dane.gov.co/ files/comunicados/cp ecultural 000.pdf

Editorial Televisa. (2014). Revista Tú. Recuperado de: http://store.editorialtelevisa.com.co/index. php?id product $=72 \&$ controller $=$ product\&id lang=1

Elias, N. (1979). El proceso de la civilización. Investigaciones sociogenéticas y psicogenéticas. México: Fondo de Cultura Económica.

Foucault, M. (1991). Historia de la sexualidad. La voluntad de saber. Vol. I. México: Siglo xxı.

FTD. (1966). Cartilla moderna de urbanidad para niñas. Bogotá: Voluntad.

Guattari, F. (1996). Regímenes, vías, sujetos. En: Incorporaciones. Madrid: Cátedra.

Herrera, C. (2010). Congreso de Marketing en Centros Comerciales. Recuperado de: http:// smpmanizales.blogspot.com.co/2010/07/elpoder-de-la-marca.html

McRobbie, A. (1998). More!: nuevas sexualidades en las revistas para chicas y mujeres. En: J. Curran, W. Valerie y D. Morley. (coords.), Estudios culturales y comunicación. Análisis, producción y consumo cultural de las políticas de identidad y el postmodernismo, (pp. 263-296). Barcelona: Paidós. 
Mercado, A. (2009) Multimedios: editorial Televisa Argentina (trabajo presentado al curso Multimedios, Aspectos Económicos y Reglamentarios). Universidad de Palermo Facultad de Ingenierías, Postgrado en TV Digital, Buenos Aires. Recuperado de: http://www.palermo. edu/ingenieria/TVDIGITALPOSGRADO/4.pdf

Minzi, V. (2006). Los chicos según la publicidad. Representaciones de infancia en el discurso del mercado de productos para niños. En: S. Carli (comp.), La cuestión de la infancia entre la escuela, la calle y el shopping. (pp. 209-240). Buenos Aires: Paidós.

Morley, D. (1996). Televisión, audiencias y estudios culturales. Buenos Aires: Amorrortu.

Postman, N. (1994). La desaparición de la niñez. Nueva York: First Vintage Books.

Quijano, V. (2006). Biopolítica, subjetividad y ecoNOmía. Vida y regulación de la desregulación. En V. Quijano y J. Tobar (comps.), Biopolítica y filosofías de vida. Popayán: Universidad del Cauca.

Raddar. (s.f.). Raddar somos. Recuperado de: http:// www.raddar.net/about.html

Revista Tú. (febrero de 2013a). Bogotá: Editorial Televisa. . (abril de 2013b). Bogotá: Editorial Televisa. . (junio de 2013c). Bogotá: Editorial Televisa. . (julio de 2013d). Bogotá: Editorial Televisa. (agosto de 2013e). Bogotá: Editorial Televisa. . (septiembre de 2013f). Bogotá: Editorial Televisa. (octubre de 2013g). Bogotá: Editorial Televisa.

Schor, J. (2006). Nacidos para comprar. Los nuevos consumidores infantiles. Barcelona: Paidós.

Steinberg, S. R.; Kincheloe, J. L. (comps.). (2000). Cultura infantil y multinacionales. Madrid: Morata.

Szir, S. (2007). Infancia y cultura visual. Recuperado de: http://coleccion.educ.ar/CDInstitucional/ contenido/entrevistas/sandra szir.html

. (2012). Entre el discurso pedagógico y la cultura del consumo en Argentina. La escuela y el periódico ilustrado Caras y Caretas (18801910). En: S. Sosenski y E. Jackson (coords.), Nuevas miradas a la historia de la infancia en América Latina. Entre prácticas y representaciones. México: Instituto de Investigaciones Históricas, Universidad Nacional Autónoma de México. Recuperado de: http://www.historicas.unam.mx/publicaciones/publicadigital/ libros/miradas/miradas.html

Walkerdine, V. (1998). La cultura popular y la erotización de las niñas. En: J. Curran, W. Valerie y D. Morley. (coords.), Estudios culturales y comunicación. Análisis, producción y consumo cultural de las políticas de identidad y el postmodernismo (pp. 153-186). Barcelona: Paidós. 